\title{
TERRITORIALIZAÇÃO DA SOJA NO CONTEXTO DA AGRICULTURA FAMILIAR NA FRONTEIRA BRASIL/URUGUAI
}

\author{
Tatiane Almeida Netto ${ }^{1}$ \\ Daiane Loreto de Vargas ${ }^{2}$
}

Resumo: Este trabalho objetiva compreender as transformações que vem ocorrendo no Pampa, em função da territorialização da soja, analisando os impactos dessas mudanças no território, especialmente referente a inserção dos agricultores e pecuaristas familiares nesse sistema de produção. O espaço de análise se concentra na zona de fronteira dos municípios de Santana do Livramento/BR e Rivera/UY. Metodologicamente, foi realizada uma pesquisa de caráter qualitativo, tomando como base dados secundários, pesquisa bibliográfica e documental, e ainda, a pesquisa de campo com agricultores familiares e técnicos. Os resultados identificam uma reconfiguração territorial do espaço rural, notabilizando-se pela implantação da sojicultora, minimizando a histórica participação da pecuária na referida região.

Palavras-chave: Pampa. Monocultura da soja. Território. Agricultura e pecuária familiar.

\section{SOYBEAN TERRITORIALIZATION IN THE CONTEXT OF FAMILY FARMING IN THE BORDER BRAZIL/URUGUAY}

Abstract: This paper aims to understand the transformations occurring in the Pampa due to the territorialization of soybean, by analyzing the impacts of these changes in the territory, especially regarding the insertion of agriculture farmers and livestock family farmers in this production system. The analysis space is concentrated in the border of the cities of Santana do Livramento/BR and Rivera/UY. Methodologically, we carried out a qualitative research based on secondary data, bibliographical and documentary research, as well as field research with family farmers and technicians. The results identify a territorial reconfiguration of the rural space, especially for the implantation of soybean culture, minimizing the historical participation of cattle production in that region.

Keywords: Pampa. Soybean monoculture. Territory. Family agriculture and farming.

\section{TERRITORIALIZACIÓN DE LA SOJA EN EL CONTEXTO DE LA AGRICULTURA FAMILIAR EN LA FRONTERA BRASIL / URUGUAY}

Resumen: Este trabajo tiene como objetivo compreender las transformaciones que estan ocurriendo e el Pampa, en función de la territorialización de la soja,analizando

\footnotetext{
${ }^{1}$ Universidade Federal do Rio Grande do Sul, Departamento de Geografia, Porto Alegre, Brasil, email: tatianetto@gmail.com, https://orcid.org/0000-0002-2980-426X.

2 Universidade Federal de Santa Maria, Departamento de Geografia, Santa Maria, Brasil, e-mail: loretodevargas@gmail.com, https://orcid.org/0000-0003-4341-0264.
} 
los impactos de esos cambios en el territorio, especialmente referente a la inserción de los agricultores y productores familiares en ese sistema de produción. El espacio de analisis está concentrado en la zona de frontera de los municípios de Santana do Livramento/ BR y Rivera/UY. Metodologicamente fue realizada una investigación de carácter cualitativo, tomando como base datos secundarios, ivestigación bibliográfica y documental, aun queda un estudio de campo con agricultores familiares y técnicos en dicha región. Los resultados identifican una reconfiguración territorial del espacío rural, destacándose por la implantación de la sojicultura, minimizando la histórica participación de la producíon ganadera en la referida región.

Palabras clave: Pampa. Monocultura de la soja. Territorio. Productores y ganaderos familiares.

\section{Introdução}

O território se configura através das relações sociais marcadas pelo poder no cotidiano do homem, neste sentido diversos estudos frente ao avanço de monocultivos no Pampa identificam mudanças no território da agricultura familiar, este está sendo transformado frente as novas relações econômicas e sociais advindas de sistemas de produção diversos.

$\mathrm{Na}$ atualidade existe uma diversidade na agricultura familiar, famílias dinâmicas, tecnificadas, pluriativas, modernas, que se articulam ao mercado através de uma racionalidade em que suas bases de reprodução social estão determinadas e fundamentadas por uma sociedade cujo denominador comum é o caráter mercantil e monetário da economia. Nesse sentido, em alguns cenários a agricultura familiar presente nas áreas de fronteira possui um histórico marcado por constantes luta pelo seu reconhecimento, tanto no que se refere à sua importância econômica quanto social, por vezes sendo condicionada a mudanças em relação aos fatores de produção.

$\mathrm{Na}$ fronteira Livramento/BR e Rivera/UY identificamos a territorialização da soja, advindas da modificação do sistema produtivo agrícola, impulsionada por acordos comerciais e a vinculação ao capital estrangeiro. Ao identificarmos o avanço destes sistemas produtivos em propriedades agrícolas familiares, na última década, observamos a reorganização do espaço, das formas de trabalho ligadas a estes cultivos e a introdução de novas relações sociais com a transformação em seu arranjo produtivo influenciada pela abordagem do capitalismo agrário que transforma o espaço inserindo no território novos agentes sociais em disputa. 
Essa dinâmica está presente no contexto da agricultura familiar do Brasil e do Uruguai, embora essa categoria social possua diferenciações em termos de tamanho da unidade de produção nos dois países, em ambos mantêm a definição embasadas na forma de produção que utiliza mão de obra familiar e gestão com a presença da família.

O reconhecimento da categoria da agricultura familiar é recente nos dois países, no Brasil a partir da lei da Política da Agricultura familiar 11.326/2006 e no Uruguay através das Resoluções do Ministério de Ganadería Agricultura e Pesca (MGAP) no 219/2014 e no 397/2014. Tais reinvindicações são oriundas de um cenário político que avança para o entendimento que a agricultura familiar é alternativa para às questões sociais do campo, tendo em vista sua capacidade em promover um novo modelo de desenvolvimento, em virtude de uma maior capacidade de geração de trabalho e renda em relação à agricultura de tipo patronal.

A área de estudo desta pesquisa se concentra no espaço denominado zona de fronteira Brasil-Uruguai, com recorte intencional para as cidades gêmeas de Santana do Livramento e Departamento de Rivera. Na figura-1 observa-se a localização geográfica da área de estudo que compreende um total de $16.320,34 \mathrm{~km}^{2}$ de extensão territorial, sendo $6.950,34 \mathrm{Km}^{2}$ no município de Sant'Ana do Livramento e $9.370 \mathrm{~km}^{2}$ no Departamento de Rivera.

Utilizamos neste estudo o termo zona de fronteira caracterizada por uma área, ou seja, "faixas" territoriais de cada lado do limite internacional. Segundo Ministério da Integração Nacional (2005) em sua Proposta de Reestruturação do Programa de Desenvolvimento da Faixa de Fronteira este espaço abriga um alto grau de fluxo e interação entre os países vizinhos, que incide diretamente na promoção do desenvolvimento regional e da cidadania criando um meio geográfico próprio da fronteira.

Nesse sentido a zona de fronteira entre Brasil-Uruguai compreende uma área de integração política, cultural e de identidade própria, não se limitando a uma divisão espacial de 150 km segundo a constituição Brasileira (1988) a partir da linha imaginária divisória de fronteira, seja ela um limite natural ou artificial. Importante destacar que o Uruguai não apresenta lei que instrumentaliza a faixa de fronteira. 
Figura 1- Zona de Fronteira Brasil e Uruguai

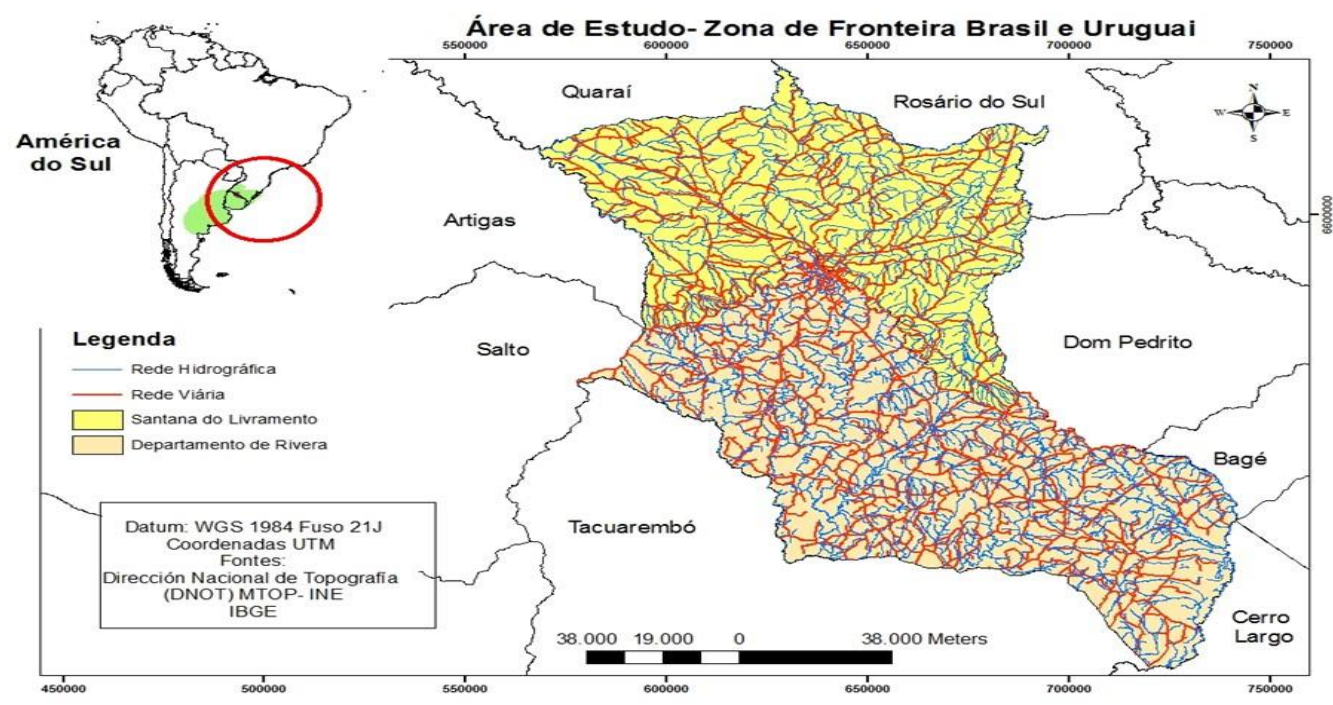

Fonte: Elaboração do primeiro autor, 2017.

Nesse sentido, este trabalho ${ }^{3}$ tem por objetivo compreender as transformações que vem ocorrendo no território da agricultura familiar, em função da territorialização da soja nesse espaço, até então, um espaço típico da pecuária extensiva. O estudo busca a análise dos impactos dessas mudanças no território, especialmente referente a inserção dos agricultores e pecuaristas familiares nesse sistema de produção, avaliando a zona de fronteira Brasil-Uruguai, considerando para tal, os municípios de Santana do Livramento/BR e Rivera/UY.

Para entender tais questões, realizamos uma pesquisa de caráter qualitativo, tomando como pressupostos elementos constituintes da pesquisa bibliográfica e documental, priorizando os dados secundários: Censos do Instituto Brasileiro de Geografia e Estatística (IBGE), Censo 2011 Uruguay, Instituto Nacional de Estadística (INE), Censo Agropecuário 2011, Estadísticas Agropecuárias (DIEA) vinculados ao Ministerio de Ganadería, Agricultura y Pesca (MGAP). Além disso, foi realizada uma pesquisa de campo no período que integra os anos de 2014 a 2016 caracterizada pela observação com registro em diário de campo e entrevista aplicados aos produtores rurais e técnicos que prestam assistência nos municípios de Santana do Livramento/BR e Rivera/UY.

Afim de cumprir com os objetivos propostos, o trabalho que segue foi estruturado em quatro seções. Primeiramente, destacando conceito de território e o contexto do Pampa, num segundo momento abordamos sobre a monocultura da

\footnotetext{
${ }^{3}$ Este trabalho é recorte de um estudo mais abrangente, o qual deu norte a um trabalho de tese.
} 
soja no contexto da agricultura familiar na zona de fronteira Livramento/BR e Rivera UY, a terceira seção destaca um breve histórico da agricultura familiar no Brasil e no Uruguai e o quarto item relata sobre os impactos da produção de soja na agricultura familiar na área de estudo. Por fim, destacamos algumas considerações finais.

\section{Conceito de território e o contexto do Pampa}

A discussão sobre o conceito de território emerge após a década de 19601970 com o surgimento da crise paradigmática positivista, a qual resulta na evolução do pensamento geográfico, com um compromisso social, cujo olhar voltou-se para as redefinições do espaço em decorrência do modo de produção capitalista. Os diferentes conceitos de território são influenciados pela realidade estudada, por seus objetivos e por sua concepção de espaço (FERNANDES, 2005, p.27).

Para Raffestin (1993) a definição de território perpassa também por um caráter político. As relações de poder se apropriam do espaço e produzem o território, formando as múltiplas territorialidades, as representações do espaço revelam a imagem do território através do controle exercido pelo poder. O território "se apoia no espaço, mas não é o espaço, é uma produção a partir do espaço. Ora, a produção, por causa de todas as relações que se envolvem, se inscreve num campo de poder" (RAFFESTIN, 1993, p.144).

$\mathrm{Na}$ concepção de Haesbaert (2004) o território pode ser interpretado a partir de três vertentes básicas: política - onde o território é analisado como um espaço delimitado e controlado, através das relações de poder político, seja do Estado ou de outros agentes; econômica - onde se destaca a relação de embate entre as classes sociais e na relação de capital-trabalho; e a cultural - onde se prioriza a dimensão simbólica e mais subjetiva, em que o território.

$\mathrm{Na}$ intepretação de Milton Santos (1998) o conceito de território passa por uma abordagem econômico-material e também por um viés político, pelas dominações de poder. $O$ autor apresenta uma concepção de território a partir da categoria de território usado, sinônimo de espaço geográfico, resultado do processo histórico da base material e social das novas ações humanas. Apresenta a existência de uma nova dinâmica territorial e enfoca conceitos como território usado, horizontalidades e verticalidades, onde afirma que o território pode ser formado por 
lugares contíguos e de lugares em rede, considerando a historicidade e o caráter híbrido.

Em relação ao contexto do Pampa, estudos identificam que o mesmo vem passando por diferentes transformações, seja em relação as questões sociais, econômicas, produtivas, ambientais e/ou culturais. São mudanças estruturais, muitas das quais influenciadas pelo cenário da globalização, impactando elementos cultuais, sociais e simbólicos desse espaço. Um exemplo é a expansão das monoculturas- extensas áreas dedicadas à produção de grãos ou outras commodities agrícolas que configuram um modelo produtivo denominado agronegócio ou agrobusiness (DAVID, 2017).

A dinâmica do agronegócio no Pampa introduziu novos elementos no território, influenciando nas relações econômicas e políticas do mesmo, como ressaltava anteriormente os autores Raffestin (1993), Santos (1994; 1998) e Haesbaert (2004). As novas reações que se estabeleceram nesse território desconsideram as especificidades do local, acabam por impactar de diferentes formas o modo de vida e as relações de trabalho dos sujeitos que habitam tal espaço.

Um exemplo claro nesse sentido é a expansão das grandes empresas capitalistas nacionais e transnacionais, dos grandes monopólios financeiros, onde se expressa um modelo de desenvolvimento pautado nas grandes produções de monocultivos com objetivo de exportar matéria-prima, ocasionando perda da biodiversidade e da cultura das populações locais (DAVID, 2017). O predomínio das políticas e das ações de poder que favorecem o cenário do agronegócio no espaço do Pampa, acabam por dificultar a permanência de agricultores e pecuaristas familiares ${ }^{4}$ no campo.

O agronegócio é a rede formada por todos os setores econômicos que giram em torno da produção agrícola e pecuária, desde o setor financeiro, passando pelo comércio, serviços, transporte, distribuição e processamento. O agronegócio ou agrobusiness, ao se expandir espacialmente, avança sobre áreas anteriormente ocupadas pelos povos do campo. Essa expansão não se faz sem conflitos.

\footnotetext{
${ }^{4}$ Aqueles que permanecem em suas pequenas propriedades enfrentam uma série de reveses, entre eles, o acesso a benefícios tradicionalmente considerados urbanos, como saúde, educação e saneamento básico, essenciais para melhorar a qualidade de vida das famílias do campo.
} 
Frequentemente, os territórios do agronegócio substituem ou sobrepõem-se aos territórios tradicionalmente ocupados (DAVID, 2017).

Portanto, no cenário contemporâneo, os campos naturais do Pampa e a sua biodiversidade socioambiental e cultural associada estão em ritmo acelerado de desaparecimento, tendo em vista o avanço das áreas agrícolas sobre os campos da pecuária e enfim, os ecossistemas campestres, especialmente da commoditie soja (CHOMENKO, 2017). Esse cenário impacta fortemente as territorialidades rurais tradicionais, especialmente aqueles que se reproduzem socioeconomicamente com base nos elementos culturais da sociobiodiversidade desse território, tais como os agricultores e pecuaristas familiares.

\section{Breve histórico da agricultura familiar no Brasil e no Uruguai}

Nos dois países existe uma diversidade na exploração familiar, as quais são derivadas de situações particulares vinculadas a diferentes contextos socioeconômicos, históricos e culturais. Lamarche (1993) e Schneider (2006), dentre outros autores, observam que existe uma multiplicidade de termos que identificam os agentes sociais envolvidos dentro da categoria agricultor familiar: produtor agrícola, cultivador da terra, camponês, colonos, sitiantes, pequeno produtor, agricultor de subsistência, etc. Tais termos revelam a complexidade do tema, comprovando que a conjuntura da agricultura familiar vai desde a exploração familiar para o autoconsumo, até aqueles totalmente integrados a economia de mercado.

No Brasil a agricultura familiar é caracterizada como uma categoria social e produtiva, fato decorrente de um conjunto de lutas e disputas que ganharam força com a abertura democrática do país e com a Constituição de 1988. Além da pressão dos movimentos sociais, de estudos de alguns intelectuais, de algumas forças políticas e da Confederação Nacional dos Trabalhadores na Agricultura. Esse conjunto de esforços propunha a necessidade de criação de políticas públicas diferenciadas para este público do rural, em 1996 cria-se o Programa Nacional de Fortalecimento da Agricultura Familiar (PRONAF) (SCHNEIDER, 2006).

Essa categoria somente foi regulamentada pela Lei Brasileira nำ11.326/2006, a qual estabelece a Política da Agricultura Familiar. No seu Art. $3^{\circ}$ considera agricultor familiar e empreendedor familiar rural aquele que pratica atividades no meio rural, atendendo, simultaneamente, aos seguintes requisitos: I - Não detenha, a 
qualquer título, área maior do que 4 (quatro) módulos fiscais; II - Utilize predominantemente mão-de-obra da própria família nas atividades econômicas do seu estabelecimento ou empreendimento; III - Tenha renda familiar predominantemente originada de atividades econômicas vinculadas ao próprio estabelecimento ou empreendimento; IV - Dirija seu estabelecimento ou empreendimento com sua família

Em termos de país, os estabelecimentos agropecuários de cunho familiar representam $86 \%$ do total das propriedades rurais no Brasil, representando $31 \%$ do total de área plantada. Em relação ao estado do Rio Grande do Sul (RS), a agricultura familiar participa com uma área plantada de 38,7\% de lavouras temporárias e $73,2 \%$ de área de lavouras permanentes plantadas no Estado (IBGE, 2006).

No Pampa gaúcho, a histórica da produção agrícola e da pecuária se assemelha a dos nossos vizinhos uruguaios. A agricultura até meados do século XX foi considerada uma atividade complementar, reduzida a uma cultura de auto sustento, salvo as áreas orizícolas nas terras mais baixas da campanha gaúcha (ROCHA, 2000). Os estancieiros integrantes da metade sul do RS, mantiveram-se por muito tempo em uma mesma atividade econômica, a pecuária extensiva e seus subprodutos, primeiramente o charque, depois a carne e a lã. A partir de 1970 visualiza-se na metade sul do RS, a inserção de cultivos nas lavouras temporárias, como sorgo forrageiro, soja e milho.

Nas unidades familiares a lavoura permanente foi ganhando espaço junto a pecuária, podemos ponderar que tal processo de mudança no sistema produtivo, com a inserção da produção da soja e milho (lavoura temporária) e de algumas áreas de hortifrutigranjeiros, teve embasamento em incentivos da Empresa Assistência Técnica e Extensão Rural (EMATER/ASCAR), através de trabalhos de extensão rural, com incentivo de algumas políticas públicas a nível estadual e federal, tal as linhas de custeio e investimento do PRONAF.

A história de ocupação e produção agropecuária do Uruguai se assemelha a história do Brasil, apresenta a introdução do gado pelas missões jesuíticas no século XVII, no século XVIII destaca-se como produtor de couro e charque, e no final do século XIX, como fornecedor de carnes e de lã para a Europa. Assim como no Brasil, a agricultura presente neste período (século XVII ao século XIX) se 
manifestava de forma marginal para autoconsumo e abastecimento das cidades (PIÑEIRO, 2009).

Foi somente no século XX, entre as décadas de 1940 a 1960, período conhecido como Neo-Batllismo ${ }^{5}$ que 0 Uruguai passou por uma reformulação econômica política e social num processo de modernização, conhecido como o período de um Estado regulador da economia e promotor de bem-estar social. Os agricultores foram aliados do projeto reformista de Batle, porque padeciam de dificuldades ocasionadas pelo latifúndio principalmente pelos altos preços de arrendamento. A proposta de Batle foi o início da diversificação da produção do Uruguai associando a pecuária a agricultura (MOSCATELLI, 1999).

A agricultura familiar foi regulamentada no Uruguai através das Resoluções do Ministério de Ganadería Agricultura e Pesca (MGAP) no 219/2014 e no 397/2014. Tal como ocorreu no Brasil, cabe esclarecer que tal distinção se faz necessária para fins de acesso a políticas públicas e decorre de um movimento ampliado, no sentido de garantir a diversificação de tratamento para grupos sociais historicamente invisibilizados, O Uruguai apresenta um total de $56 \%$ de produtores familiares em todo País, em uma área de $14 \%$ da superfície do País.

A definição de produtor familiar no Uruguai é redigida pelas Resoluções MGAP 219/14 e 397/14, as quais definem que produtores/as familiares são pessoas físicas que, com ou sem a ajuda de outros, gerenciam diretamente uma exploração agropecuária e/ou realiza uma atividade produtiva agrária que não requer o uso direto da terra.

Esta pessoa, em conjunto com sua família, deve cumprir os seguintes requisitos simultaneamente: realizar a exploração com a contratação de, no máximo, dois assalariados não familiares permanentes ou seu equivalente em jornadas de trabalho não familiares (500 horas ao ano); explorar no total até 500 hectares, sob qualquer forma de posse; residir na exploração ou a uma distância menor a $50 \mathrm{~km}$

\footnotetext{
${ }^{5} \mathrm{O}$ Batllismo foi um período reformista do governo uruguaio, no período das três primeiras décadas do século XX, incluiu os governos de José Batlle y Ordoñez. Entretanto o período denominado neobatllismo incluiu presidencialistas e colegiados de Luis Batlle Berres (sobrinho de José Batlle y Ordoñez) no governo nas décadas de 40 e 50. No âmbito social, promoveu uma intensa legislação trabalhista, estimulou a agricultura familiar e desenvolveu vários projetos vinculados a educação, proteção à infância e adolescência, direitos da mulher e saúde pública que, transformaram-se em leis durante as primeiras décadas do século XX (MOSCATELLI, 1999.).
} 
da mesma; rendas familiares nominais extras devem ser inferiores ou iguais a 14 BPC (Base de Prestaciones y Contribuciones) média mensal ${ }^{6}$ (MGAP, 2014).

Para Moraes (1998) as formas familiares da agricultura do Uruguai estão historicamente relacionadas a estabelecimentos agropecuários onde predomina a mão de obra familiar e não assalariada, a produção não está vinculada a acumulação do capital, embora os produtores sejam os proprietários da terra. Para a mesma autora a peculiaridade da agricultura familiar uruguaia se remete a sua origem, pecuaristas excluídos da estância moderna no fim do século XIX ao contrário do RS que remete a uma base indígena, de agricultores pré-coloniais e coloniais, e ainda imigrantes europeus.

\section{Monocultura da soja no contexto da agricultura familiar na zona de fronteira Livramento/BR e Rivera UY}

A dinâmica produtiva da fronteira Livramento/BR e Rivera /UY está alicerçada em sua composição florística e em seus aspectos históricos de formação territorial. Os primeiros colonizadores encontraram nessas paisagens campestres que favoreceram a inserção da pecuária extensiva (CHOMENKO, 2017). Segundo Bilenca e Miñarro (2004) historicamente o uso dos campos são destinados a zonas de pastagem e se modificam com a introdução da agricultura.

$\mathrm{Na}$ atualidade a fronteira Livramento/BR e Rivera /UY apresenta uma estrutura agrária complexa, com diversos sujeitos sociais, composta por empresários tradicionais e modernos (fortemente capitalizados e ligados a complexos agroindustriais), agricultores e pecuaristas familiares pluriativos ou não, trabalhadores assalariados, trabalhadores sem-terra e assentados de reforma agrária.

Observamos que a espacialização da soja nesse território advém do agronegócio, o qual teve origem no território da fronteira no início da década de 1990, a partir da reinvenção do produtor rural diferenciado, denominado "agropecuarista" (PIÑEIRO, 2012). O agropecuarista, ou seja, aquele que consorcia atividades agrícolas com pecuária, realiza constantes inversões tecnológicas sobre a terra para garantir a produtividade, complementa sua produção pecuária com diversos cultivos agrícolas (arroz, cereais, oleaginosas, silvicultura, dentre outros).

${ }^{6} \mathrm{O}$ valor em 2017 da BPC equivale a 2.819 pesos, o que eleva a cifra a 39.466 pesos. 
Através das observações da pesquisa, da análise dos dados secundários de censos agropecuários do Brasil e do Uruguai e das informações coletadas junto aos informantes qualificados, podemos identificar a territorialização da cadeia da soja na zona de fronteira entre os dois países (Figura-2). E ainda, as transformações que vem ocorrendo no território decorrentes da intensificação da expansão agrícola, com base na monocultura, especialmente sobre as zonas de pecuária, seja do agropecuarista (mais integrado as cadeias do agronegócio) ou dos agricultores e pecuaristas familiares tradicionais (menos integrado as cadeias do agronegócio).

Figura 2- Territorialização da soja na fronteira Livramento/BR e Rivera/UY

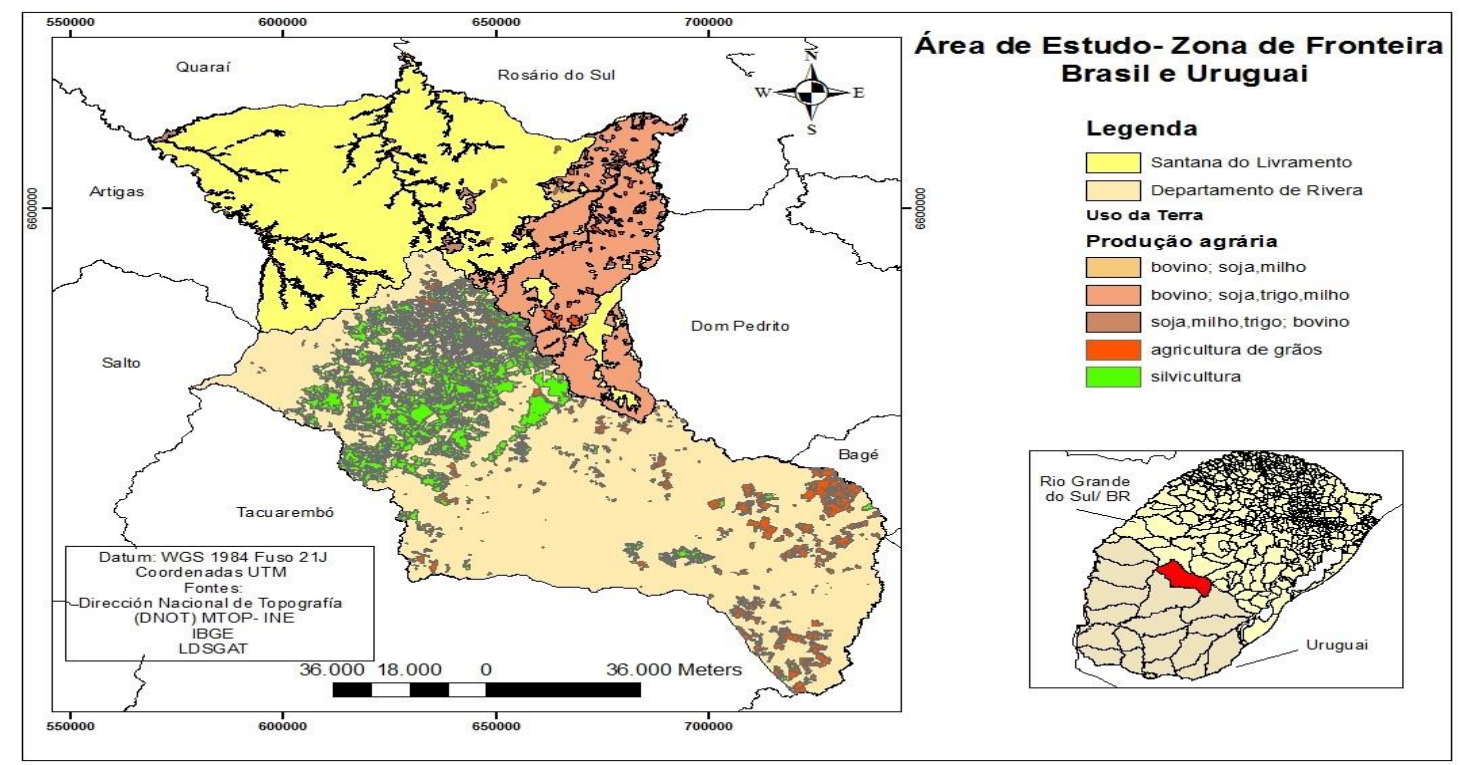

Fonte: Elaborado pelo primeiro autor, 2017.

Através de dados do IBGE (2014) visualiza-se um aumento na área plantada no município de Sant'Ana do Livramento, no ano de 2004, segundo dados da produção agrícola municipal, equivalia a 4.700 ha, já em 2013 se apresenta um total de área plantada de 29.100 há (Figura -3). Já a área de cultivo de arroz houve uma diminuição, em 2004 a área plantada era de 11.400 ha em 2013 apresentava-se uma área plantada de 8.627 ha. Esses dados comprovam a substituição da cultura do arroz pela soja. 
Figura 3 - Gráfico referente a produção de soja no município de Sant'Ana do Livramento

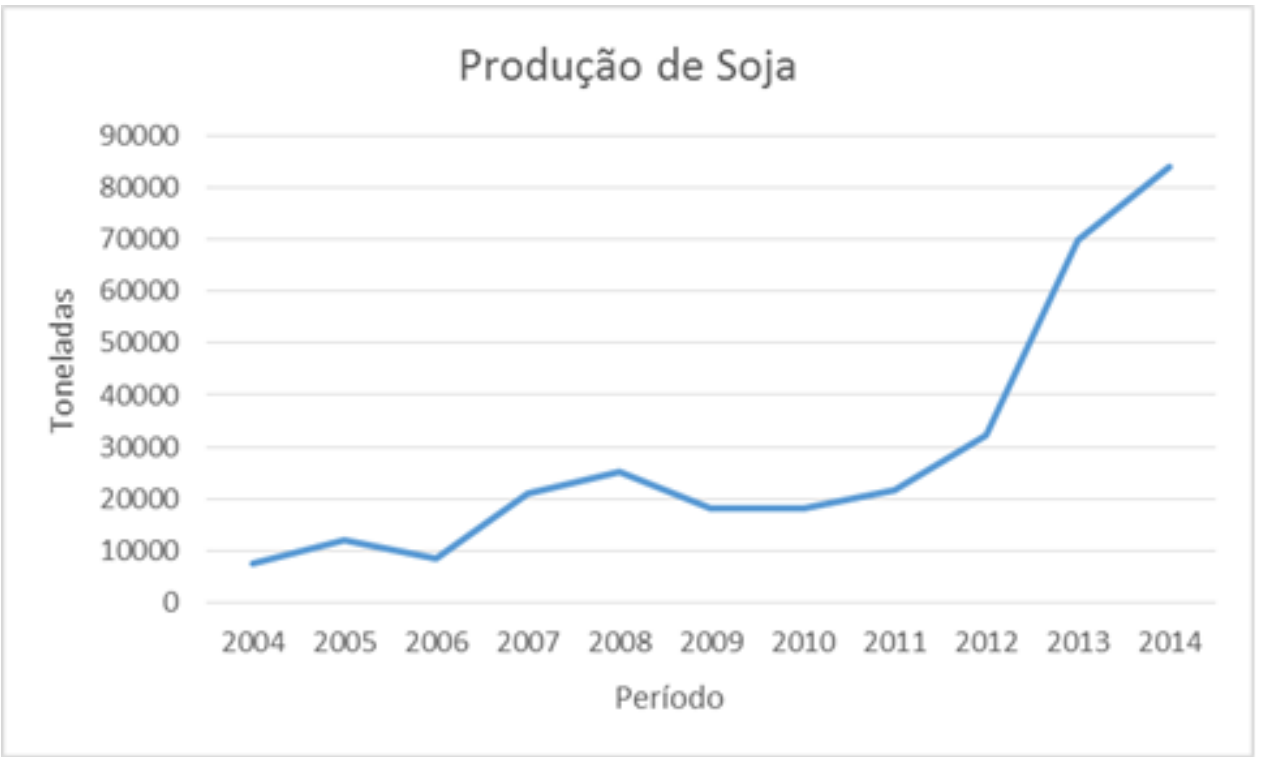

Fonte: Elaborado pela autora, a partir dos dados do IBGE, 2013.

Em questionamento aos informantes qualificados, todos eles responderam ser visíveis as mudanças na dinâmica produtiva no território da fronteira, especialmente na última década. A questão que mais se destaca na fala dos entrevistados, é a transformação do tradicional sistema produtivo, a pecuária de corte de forma extensiva, que está cedendo espaço a agricultura moderna, principalmente a soja. Estas transformações são decorrentes das políticas desenvolvimentistas aplicadas nesse território, as quais vêm acarretando fortes interferências nas relações com a natureza e com a sociedade. Assim, a incorporação de novas cadeias produtivas tornou-se um fenômeno atuante nesse espaço (CANCELIER, KASSOL E NETTO, 2017).

Em relação a Rivera, observou-se também um aumento na área de plantio de soja, principalmente na zona de Vichadero. Não existem dados específicos do plantio de soja no Departamento de Rivera e sim uma estimativa que varia entre 15.000 a 20.000 hectares de área plantada da leguminosa. De acordo com os informantes qualificados, o capital investido no cultivo de soja está associado ao capital Argentino. Vale também destacar a proximidade entre a localidade de Vichadero/UY e o Município de Bagé no Brasil, onde ocorre um aumento significativo no plantio de soja.

A área de produção de grãos pode ser identificada no mapeamento da área de grãos em Rivera, conforme figura - 4. Os documentos consultados, bem como os 
relatos dos depoentes, evidenciam que o aumento da área de soja é consequência a rotação de cultivos adotada pelos produtores, pois os mesmos optam pelo plantio da leguminosa para fazer a rotação de cultivos nas lavouras de arroz. Com o passar das safras os produtores acabam sempre aumentando a área de plantio de soja devido a rentabilidade, o preço da soja e os incentivos por parte do poder público e agentes econômicos.

Figura 4- Espacialização da agricultura de grãos, incluindo a soja em Rivera/UY.
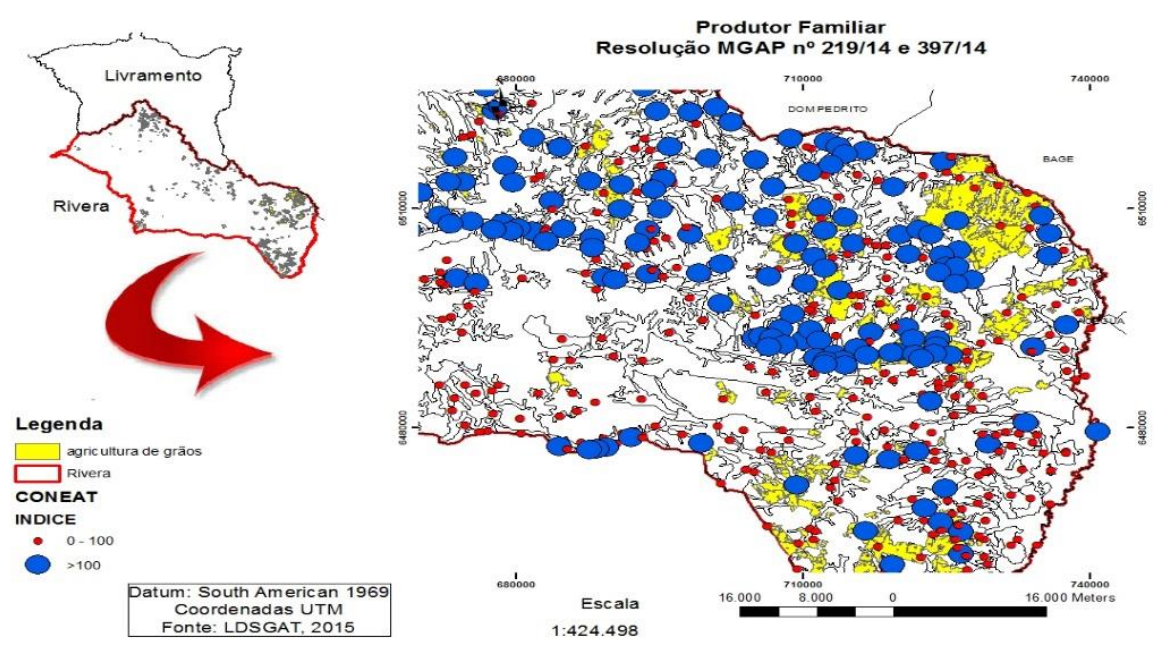

Fonte: Elaborado pelo primeiro autor, 2017.

Analisando os dados apresentados, em relação aos dois municípios, percebemos que a soja avança rapidamente sobre o Pampa e esse avanço altera profundamente a base produtiva e fundiária deste espaço. A soja, como um dos principais representantes do modelo agroexportador de sustentação da política neoextrativista, representa a cultura agrícola que mais cresceu em área plantada nesse território nas últimas décadas (FIGUEIRÓ, 2017). E ainda, esse crescimento tem avançado sobre as pequenas e médias propriedades, ocasionando alterações no território, com a ampliação da concentração de terras, tecnificação e despovoamento.

\section{Os impactos da produção de soja na agricultura familiar}

Os agricultores familiares presentes no território da fronteira Livramento/BR e Rivera /UY modificam suas relações sociais a partir da dinâmica agrícola inserida no espaço. Nesse sentido, a cadeia da soja atribui conflitos ao território da agricultura 
familiar, frente aos novos desafios o agricultor familiar modifica suas estratégias de reprodução social, consorciando suas atividades com as cadeias do agronegócio já territorializadas no Pampa.

As relações sociais formadas a partir das intencionalidades do sujeito produzem o território. A intencionalidade é definida por Fernandes (2005), inspirada em Lefebvre, como um modo de concepção que atores coletivos e sujeitos utilizam para se materializarem no espaço, constitui-se uma identidade uma visão de mundo, de ser e de existir. Assim, em função da inserção da soja, os dois municípios em estudo experimentaram significativos processos de transformação na dinâmica territorial e nas relações que daí derivam.

Um dos impactos relevantes está no fato que a cadeia de soja imprime ao agricultor familiar uma característica empresarial, devido a própria dinâmica da cadeia produtiva, visto que se trata de um cultivo com baixa diferenciação do produto final, sendo fundamental o ganho de escala, a otimização da tecnologia e a negociação de grandes volumes para reduzir custos e ampliar a rentabilidade. $\mathrm{O}$ agricultor passa a ter uma relação com o uso de novas tecnologias, com o plantio direto e o uso de sementes geneticamente modificadas, afim de aumentar a produtividade e a rentabilidade da produção.

Bartra (2006) identifica que a intensificação de pacotes tecnológicos emerge no intuito de criar uma natureza com imagem e semelhança do capital, como exemplo o uso de transgênicos, nanotecnologias e agricultura de precisão.

O capital quando acessa o campo tem que diversificar tecnologias, modos de acesso à terra e padrões produtivos. Milton Santos (1994) destaca que esta modernização gera modificações nas repercussões geográficas, na configuração territorial, a história atribui funções diferentes ao mesmo lugar. Os lugares podem até permanecer os mesmos, mas as situações se modificam, transformam-se as funções e modificam-se as estruturas emergindo novas formas de organização espacial.

As transformações realizadas na fronteira Livramento/BR e Rivera/UY na última década ocasionaram uma reconfiguração territorial do espaço rural, a qual é consolidada e instituída pelos novos sujeitos territoriais, sujeitos estes oriundos do território do agronegócio e da agricultura familiar. Neste sentido, identificamos a territorizalização da soja, que segundo Pedon $(2009$, p.15) territorialização refere-se 
ao processo pelo qual se torna concreta a apropriação política do espaço, resultando na tarefa da administração e no exercício do comando.

Nesse sentido, a sojicultora permite que também se instalem no território novos atores e novas relações sociais são originadas, impactando a agricultura familiar. Em Sant'Ana do Livramento no final de dezembro de 2016 se instalou na região duas cooperativas a Cooperativa Agropecuária Júlio de Castilhos (COTRIJUC) e a Cooperativa Tritícola Sepeense (COTRISEL), que atuam em conjunto, para o desenvolvimento da produção sojífera.

$\mathrm{Na}$ intepretação dos representantes destas cooperativas, o surgimento das cooperativas ocorreu no sentido de organizar o mercado da cadeia da soja. No território percebe-se a aceitação do discurso das instituições, as quais declara que as cooperativas são canais que permitem que os agricultores acessem ao mercado e as informações sobre as tecnologias modernas. Além disso, as instituições destacam que atuam para diluição os riscos, oferecendo assistência técnica, venda de insumos com planos pós-safra.

O território também comporta a Cooperativa da Agrosoja Santana, a qual atua diretamente na cadeia de soja oferecendo insumos e apoio à comercialização. A Agrosoja iniciou seus serviços em Sant'Ana do Livramento no ano de 2005 e segundo os técnicos entrevistados, atualmente a cooperativa encontra-se em ampliação, contando com uma filial na localidade de Coxilha Santo Ignácio e aumentando o seu parque operacional na sua sede, na localidade de Faxina, para receber e armazenar mais grãos.

Também ficou evidenciado na pesquisa de campo que as cooperativas presentes no espaço atribuem o papel de repasse de insumos ao agricultor; contratam a compra do grão com preço fixo antes do plantio, com volume para assegurar o pagamento dos insumos; estimulam o produtor a plantar a soja com a tecnologia indicada; contratam antecipadamente a venda do grão com as agroindústrias com preço fixo e acompanham tecnicamente o plantio e às lavouras.

São fatores do modelo dominante do agronegócio, com aporte do modelo de difusão de tecnologias modernas e acesso aos mercados globais. Para Milton Santos (1998) a existência de uma nova dinâmica territorial é determinada a partir do avanço da mundialização, na qual ele destaca o meio técnico-científico informacional que marca o avanço de novos sistemas de produção que demandam o desenvolvimento. Para o autor, as redes que compreendem os espaços rurais 
atuais, envolvem as empresas, nacionais e multinacionais, os serviços existentes, públicos e privados que demandam a interação entre estes diversos sujeitos presente neste espaço, construindo novas identidades sociais no território.

Parte dos agricultores familiares que permanecem nesse território de fronteira estão se transformando em empresários, especializam-se em suas tarefas por meio de reorganização do trabalho na sua unidade de produção, os informantes qualificados já descrevem a incorporação de serviços num processo de terceirização de trabalho e mão de obra diminuindo custos. Entre as estratégias adotadas podemos ainda observar a especialização técnica, a capacitação dos recursos humanos, para trabalharem no manejo, na gestão e com equipamentos modernos.

Já aqueles agricultores que resistem a esse modelo buscam manter-se no campo com a realização da pecuária familiar e com atividades agrícolas e nãoagrícolas, dentre e fora da propriedade, alguns tornam-se pluriativos, inclusive vendendo parte de sua mão de obra para atividades voltadas ao agronegócio na região e a cadeia da soja, por vezes tornam-se empregados temporários nas lavouras. Enfim, observa-se uma diversidade de estratégias de reprodução social nesse contexto.

Em relação a produção nas propriedades dos pecuaristas e agricultores familiares, enfrentam uma série de percalços, tais como a falta de assistência técnica e de acesso as políticas públicas, dificuldades estruturais e de acesso aos mercados. $E$ ainda, são impactados pelas questões ambientais do modelo sojicultor adotado no território e pelos fenômenos sociais que desse modelo decorre, como o esvaziamento do campo.

A produção da monocultura da soja também impacta sobre as questões ambientais, as entrevistas com os informantes qualificados em referência ao impacto da soja na água, fauna e flora local, aponta que $74 \%$ dos entrevistados declaram que este impacto existe e tem consciência deste fato, 15,8\% não quiseram responder ou não apresentavam opinião formada. Mas, interessante o dado de que, apenas $10 \%$ dos entrevistados acreditam que a soja não tem impacto ambiental em sua propriedade.

Para Nabinger et, al. (2009), o uso de herbicidas de alto impacto necessários para a produção da soja, como o glifosato, degrada o solo de maneira quase irreversível e elimina a biodiversidade, dificultando ao agricultor familiar o retorno a sua atividade original. Além disso, a soja se caracteriza por um cultivo intensivo e 
tem uma demanda elevada de recursos: principalmente de energia, água, agrotóxicos e solo. Qualquer mudança na vegetação natural ou em terras de pastoreio transformando em plantações aumenta a erosão do solo e altera o ciclo hidrológico.

Para Chomenko (2017), o Pampa está em um ritmo acelerado de perda de biodiversidade, em função da introdução das monoculturas, como a soja. Enfim, a biodiversidade desse território tem sido afetada pela monocultura da soja e pelos impactos do agronegócio exportador, modificando o ecossistema, interferindo no equilíbrio e na balança dos serviços ambientais ecossistêmicos, modifica a qualidade da água de determinadas comunidades rurais, do solo e também a polinização e o controle de pragas. Gerando um cenário de insustentabilidade socioambiental no território do Pampa.

\section{Considerações finais}

Analisando as transformações na zona de fronteira Livramento/BR e Rivera/UY resultantes da nova reconfiguração territorial do espaço e das relações sociedade e natureza, identificamos que os dois municípios em estudo experimentam significativos processos de transformação na dinâmica agrária pela inserção da soja gerando conflitualidade na agricultura familiar. Portanto, esse território tem sido influenciado constantemente devido aos incentivos por parte do poder público, agentes econômicos no sentido de fomentar a integração lavourapecuária.

$\mathrm{Na}$ cadeia da soja podemos perceber a utilização de serviços terceirizados que exigem a especialização técnica, o conhecimento, o que favorece a presença de um novo ator no território: o técnico que atua junto as cooperativas e oferece suporte técnico as unidades de produção. Os documentos consultados, bem como os relatos dos depoentes evidenciam uma mudança no comportamento empreendedor do agricultor familiar, no qual a busca pela produtividade, rentabilidade e capital de giro faz com que ele aumente a área de soja plantada, aumentado também as áreas de plantio de campo melhorado, introduzindo espécies exóticas e com isso alterando a biodiversidade local.

Nesse sentido, podemos apontar que a territorialização da soja transforma a cadeia produtiva em ator local que compete pelo território, controlando e 
demandando novos processos econômicos sociais e políticos, adotam táticas ligadas a responsabilidade social implicando na sensibilização/convencimento da adequação de suas atividades.

Por fim, consideramos que os maiores impactos do avanço do cultivo da soja sobre o Pampa estão relacionados a perda da biodiversidade e novas relações sociais introduzidas no território. Na medida que se modifica o ecossistema, interferindo no equilíbrio e na balança dos serviços ambientais ecossistêmicos, também se modifica a qualidade da água, do solo, até a polinização e controle de pragas. No momento em que novos atores passam a atuar no território, os agricultores e pecuaristas familiares passam a estar inseridos em um contexto de novas relações sociais, políticas, econômicas e de poder, buscando se adaptar e/ou reconstruir seu espaço.

\section{REFERÊNCIAS}

BARTRA, A. Del Capitan Swing a José Bové: los trabajadores del campo contra el hombre de hierro. Análisis Latinoamericano del medio rural. Nueva época №4. VII Congreso de la Asociación Latinoamericana de Sociología Rural (ALASRU). Universidad Autónoma de Chapingo. Chapingo México.2006.p. 137-156.

BILENCA, D. MIÑARRO, F. Identificación de Áreas Valiosas de Pastizal (AVPs) em las Pampas y campos de Argentina, Uruguay y Sur de Brasil. Fundación Vida Silvestre Argentina. Buenos Aires. 2004. p. 353.

CANCELIER, J. W; KASSOL, K, P; NETTO, T. A. A ação do capital no território do Pampa. In: WIZNIEWSKY, C.R.; F.; FOLETO, L. M. (Org.) s. Olhares sobre o Pampa: um território em disputa. Porto Alegre: Editora Evangraf, p.169-179, 2017.

CHOMENKO, L. Transformações estruturais no Pampa. In: WIZNIEWSKY, C.R.; F.;

FOLETO, L. M. (Org.) s. Olhares sobre o Pampa: um território em disputa. Porto Alegre: Editora Evangraf, p.62-77, 2017.

DAVID, C. De. Antropologia das populações rurais. 1. ed. NTE, UAB, UFSM. E-book. Santa Maria, RS, 20

FERNANDES, B. M. Movimentos socioterritoriais e movimentos socioespaciais: contribuição teórica para uma leitura geográfica dos movimentos sociais. Revista NERA - ANO 8, N. 6 jan.jun. de 2005. p.24-34.

FIGUERÓ, A. S. Transformações na paisagem do Pampa: a territorialização do capital e a monopolização do território. In: WIZNIEWSKY, C.R.; F.; FOLETO, L. M. (Org.) s. Olhares sobre o Pampa: um território em disputa. Porto Alegre: Editora Evangraf, p.140-168, 2017.

HAESBAERT, R. da C. O mito da desterritorialização: do "fim dos territórios" à multiterritorialidade. Rio de Janeiro: Bertrand Brasil, 2004 
INSTITUTO BRASILEIRO DE GEOGRAFIA E ESTATÍSTICA - IBGE. Produção Agrícola Municipal 2013. Rio de Janeiro: IBGE, 2014

INSTITUTO NACIONAL DE COLONIZAÇÃO E REFORMA AGRÁRIA. Relatório Ambiental do Projeto de Assentamento Santo Ângelo: Sant'Ana do Livramento/RS. Porto Alegre, 2006.

LAMARCHE, H. (Coord.) A Agricultura Familiar: comparação internacional. Tradução: Ângela Maria Naoko Tijiwa. Campinas, SP, Editora da UNICAMP, 1993.

MGAP. Registro de productores familiares. 2014. Disponível em: $<$ http://www.mgap.gub.uy/portal/page.aspx?2,drural,drural-registro-de-productoresfamiliares, $\mathrm{O}, \mathrm{es}, 0,>$. Acesso em: 24 jun. 2015.

BRASIL. MINISTÉRIO DA INTEGRAÇÃO NACIONAL. Secretaria de Programas Regionais. Programa de Desenvolvimento da Faixa de Fronteira. Proposta de Reestruturação do Programa de Desenvolvimento da Faixa de Fronteira/Ministério da Integração Nacional, Secretaria de Programas Regionais, Programa de Desenvolvimento da Faixa de Fronteira - Brasília: Ministério da Integração Nacional, 2005.

MORAES, M. I. Estado de la cuestión agraria en el Uruguay y fuentes para su estudio. América Latina en la Historia Económica, [S.I.], p. pp. 35-50, jan. 1998.

MOSCATELLI, M. Uruguay. La propuesta del batllismo: democracia política+ democracia social, una combinación ideal para una democracia real. La Trama de la Comunicación, v. 4, p. 327-339, 1999.

NABINGER, C. et, al. Produção animal com base no campo nativo: aplicações de resultados de pesquisa. In: PILLAR, V.P.; MÜLLER, S.C.; CASTILHOS, Z.M.S. e JACQUES, A.V.A. (Org.)s. Campos Sulinos, conservação e uso sustentável da biodiversidade. 1. ed. Brasília/DF: Ministério do Meio- Ambiente p. 175-198, 2009

PEDON, N. R. Movimentos Socioterritoriais: Uma Contribuição Conceitual à Pesquisa Geográfica. Tese Doutorado (Programa de Pós-graduação em Geografia da FCT Faculdade de Ciências e Tecnologia da UNESP -Universidade Estadual Paulista). Presidente Prudente, 2009.

PIÑEIRO, D. Asalto a la Tierra: el capital financiero descubre el campo uruguayo. In: (Org.) Guillermo Almeyra, João Márcio Mendes Pereira, Luciano Concheiro, Carlos Walter PortoGonçalves. Capitalismo, terra e poder na América Latina (1982-2012). Editora Siglo XXI. México.2012.

RAFFESTIN, Cl. Por uma geografia do poder. Tradução de Maria Cecília França. São Paulo: Ática, 1993.

ROCHA, J. M. da. As raízes do declínio econômico da "Metade Sul" do Rio Grande do Sul uma análise da racionalidade econômica dos agentes produtivos da região. Primeiras Jornadas de História Regional Comparada, 1., 2000, Porto Alegre. Anais... Porto Alegre: Fee, 2000. Online. Disponível em:

<http://www.fee.com.br/sitefee/download/jornadas/1/s12a5.pdf> Acesso em 12 de dez. de 2018.

SANTOS, M. (Org.). Território: globalização e fragmentação. São Paulo: HUCITEC, 1994. 
SANTOS, M. Técnica, espaço, tempo: globalização e meio técnico-científico informacional. 4. ed. São Paulo: Hucitec, 1998.

SCHNEIDER, S. Agricultura familiar e desenvolvimento rural endógeno: elementos teóricos e um estudo de caso. In: FROEHLICH, J.M.; DIESEL, V (Org)s. Desenvolvimento Rural: tendências e debates contemporâneos. Unijuí, ljuí. 2006.

\section{NOTAS DE AUTOR}

\section{CONTRIBUIÇÃO DE AUTORIA}

Tatiane Almeida Netto - Concepção. Coleta de dados, Análise de dados, Elaboração do manuscrito, revisão e aprovação da versão final do trabalho

Daiane Loreto de Vargas - Elaboração do manuscrito. Revisão e aprovação da versão final do trabalho.

\section{FINANCIAMENTO}

Pesquisa Financiada pela Capes, nível de doutorado sanduíche na região de Fronteira Brasil -Uruguai.

\section{CONSENTIMENTO DE USO DE IMAGEM}

Não se aplica.

\section{APROVAÇÃO DE COMITÊ DE ÉTICA EM PESQUISA}

Não se aplica.

\section{CONFLITO DE INTERESSES}

Não se aplica.

\section{LICENÇA DE USO}

Este artigo está licenciado sob a Licença Creative Commons CC-BY-NC. Com essa licença você pode compartilhar, adaptar, criar para qualquer fim, sem uso comercial e desde que atribua a autoria da obra.

\section{HISTÓRICO}

Recebido em: 01-02-2019

Aprovado em: 15-03-2019 